\title{
Tragedia de la tragedia: la información
}

\author{
Fecha de recepción: 01/03/2010 - Aprobación: 05/04/2010
}

\section{Rubén Darío Higuera}

\section{Resumen}

Frente a la crisis que se propicia por causa de una tragedia 0 un desastre natural, la información ha tomado posiciones dispares y se ha permitido elaborar un mensaje inteligible que falsea la noticia 0 , en su peor caso, desintegra la veracidad de los hechos. Se han elaborado libros, informes de prensa y columnas periodísticas que subvencionan la cantidad de información pero amenazan la calidad de la misma y frente a esto, es decir, frente a la tragedia una mayor sale a colación: los intereses del reportero 0 del medio y la dudosa libertad de prensa.

\section{Palabras clave}

Periodismo, tragedia, Haití, información, desastre, opinión, Chile.

\begin{abstract}
Given the crisis that is generated because of a tragedy or natural disaster, information has taken different positions and it has allowed itself to develop a comprehensive message that distorts the news or, in the worst case, disintegrates the veracity of the facts. Books, press releases and newspaper columns that subsidize the amount of information, but threaten its quality have been prepared, and compared to the greater tragedy, a bigger tragedy shows up: the interests of the reporter or media and the dubious freedom of the press.
\end{abstract}

\section{Keywords}

Journalism, tragedy, Haiti, information, disaster, opinion, Chile.

\section{Introducción}

Quien asiste a un foro o presencia una noticia no sabe si ceder al bostezo, al llanto o a la resignación. Hemos visto no sin desasosiego que la muerte de la primera década del siglo XXI trajo consigo las más asfixiantes y temibles desgracias, entre ellas, la más reciente sacudida que le auspició la tierra a la nación chilena y la casi desaparición, entre escombros, de uno de los países más pobres y desafortunados del mundo: Haití.

De esto han surgido los más inoficiosos comentarios, la prensa ha mostrado sus dientes y su destreza de manipulación y, lo que es peor, los periodistas de renombre y fama, aquellos que con ojo agudo sospechan de la crisis informativa, desperdician entre elocuencia y discurso la energía que se 
Ángel Lockard, ex embajador de Colombia en República Dominicana, sostieneque la crisis de la primera república latinoamericana $y$ negra se debe más que al infortunio de la muerte y la desaparición del poco capital humano que se había conseguido, con no poco esfuerzo, hasta el inicio de este año, $y$ que, además, -continúa, enfático $y$ decisivo-la carenciade este capital pone a flote la incapacidad de Haitípara reconstruirse. necesita para asegurar, si no, una solución, sí una ordenada participación que no disfrace la agonía ni intelectualice la tragedia.

\section{El show de la tragedia humana}

Ángel Lockard, ex embajador de Colombia en República Dominicana, sostiene que la crisis de la primera república latinoamericana y negra se debe más que al infortunio de la muerte y a la desaparición del poco capital humano que se había conseguido con no poco esfuerzo, hasta el inicio de este año y que, además, -continúa, enfático y decisivo- la carencia de este capital pone a flote la incapacidad de Haití para reconstruirse.

¡Vaya discurso señor Lockard!, parece que la fe suya, ¿o la del primer ministro de la nación que está enferma?, es un claro ejemplo de lo que significa la fe ciega, pues creer que con doscientos médicos o con un puñado de estudiantes se levanta y se reedifica una nación es creer en lo que la tradición judeocristiana a modo de cancioncilla nos ha dictado, "aquello que ojo no vio ni oído oyó".

El embajador que, además, de su destreza y su sobria manera de hablarle a un público distante, cree ser un rotundo conocedor de temas tan trágicos como la tragedia y temas tan dramáticos como la muerte. Me pregunto qué significa y qué se siente gozar de tan alto renombre y tener en sus manos la potente impotencia de no salvar

\section{Reseña de autor \\ Rubén Darío Higuera}

(Politécnico Grancolombiano)

rubenhijera @yahoo.es

Nació en Bogotá en 1981. Ha cursado estudios superiores de Música, Literatura y Periodismo. Administra el blog Pulsacionliteratia.blogspot.com la tierra con las ventas de sus libros, que por cierto, no se hicieron esperar para ser publicados entre los escombros.

Valoro, sin embargo, el corazón augusto de este hombre, su insistencia en algo estéril como lo es trasladar el dolor expandido de una nación a la estrechez de la página y la conferencia, reconozco su visión de hermandad y de dolor y su campaña de circocultura "Cantemos por ti, Haití”, que buscaba brindar una rápida ayuda económica además del aplauso del primer mandatario colombiano y el nuncio apostólico del mismo país: la tragedia convertida en show, la noticia en noticia al verse (al revés) sustituyendo la fotografía de un hospital colapsado o de un país en ruinas por la risueña figura de un hombre valeroso y esforzado. Humano, demasiado humano.

Y sigue la tierra con sus temblores... continúan los tsunamis y las réplicas que acrecientan el miedo, y con esto, surgen, acompasados y en síncope, los informantes y analistas que caricaturizan el dolor $y$ la ausencia de las víctimas. Hace poco, el prestigioso columnista del New York Times, David Brooks, aseguró que el terremoto que produjo tan nefastas y numerosas pérdidas (casi 200.000 muertos, 250.000 heridos y más de un millón de damnificados) se produjo por la ausencia de planificación que se promueve por y desde la religión vudú, además -sentenció- la culpa de tan horrendo desastre la tienen el atraso cultural y las creencias paganas de sus habitantes.

Nada mal, si se piensa en sobrevalorar a la religiosa, perdón, acostumbrada voz de un hombre brillante como el señor Brooks, pero no del todo cierto. Poco o nada tienen que ver las manifestaciones religiosas en los desastres naturales y sí mucho con las econó- 
micas, que bien quedan al descubierto con el Haití en ruinas que hoy podemos contemplar. No es la sociedad pagana la que provoca el desastre, es más bien la falta de preparación económica para un desastre la que los deja, a todos los haitianos a la intemperie; véase por ejemplo el caso de Chile, que con tan horrendas sacudidas, su cifra de muertos no llega a un $10 \%$ de la cifra tan elevada que golpeó a Haití.

Tragedia de la tragedia, al fin y al cabo, espacios televisivos que dramatizan con morbo e insistencia lo que no valía la pena repetir como si fuera el trailer de la última y muy mediocre película 2012 de Roland Emmerich. Columnistas apresurados que promueven el ateísmo mientras por otro lado inculpan a Dios de inmisericordia y asesinato; escritores de la fatalidad que envuelven el problema entre sarcasmo y burla; desentendidos que bostezan y se dejan convencer; los que culpan al vudú y se extienden como "heresiarcas" a hablar en contra de las herejías... En fin, tragedia dentro de la tragedia. Invención de la información, crisis en medio de la crisis.

\section{Entre la información y la comercialización}

Pero otras tragedias victimizan nuestro periodismo. El profesor Germán Yances Peña se empeña en develar el ya conocido "conflicto" de los medios de comunicación al verse sujetos del placer del servicio informativo y, al mismo tiempo, a la presión comercial. La ambivalencia es clara: se cuenta la noticia o se inventa, se registra o se manipula.
Hace poco nuestro país vio con no poca vergüenza la trampa constante que existe en el mundo de la información, meses atrás, luego de una columna que publicara la incisiva periodista Claudia López, y en la que con trasparencia mostró la información solventada por el diario El Tiempo, desde el compromiso con el creciente conflicto de intereses y sus propios beneficios comerciales (ganarse el tercer canal), a lo que se suma el manejo tan poco profundo de la noticia frente a agroingreso seguro (AIs). El Tiempo hizo público el despido de la periodista, tal vez porque con sus hechos narrados puso de manifiesto la inclinación gobernista y política que le hacen, más que informar, torcer la noticia.

Para no ir más lejos, por esos días de marzo de 2010, la triste y más reciente noticia que golpea al periodismo nacional es el cierre de la revista Cambio, que hoy se ve reducida a cero, luego de ser una publicación semanal y nos deja unas intensas dudas sobre la libertad de prensa y el periodismo genuino.

Tragedia al servicio de la inutilidad al fin $y$ al cabo, pero tragedia sin escombros, tragedias que desinforman y que hacen de todo desastre un espectáculo, y de la responsabilidad social de los medios de comunicación un estadio utópico del periodismo.

En semejante situación y en medio de tanto discurso político que discurre sin mesura, valdría la pena hacerse una pregunta, en un estado de opinión: ¿el periodismo de opinión termina siendo periodismo de Estado?
Tragedia de la tragedia, al fin y al cabo, espacios televisivos que dramatizan con morbo e insistencia lo que no valía la pena repetir como sifuera el trailer de la última y muy mediocre película 2012 de Roland Emmerich. 